\title{
Pre-treatment of oil palm frond biomass via extensive high temperature drying for gasification process
}

\author{
Nur Hazwani Mat Razali ${ }^{1}$, Shaharin Anwar Sulaiman ${ }^{1,}{ }^{*}$, Mohamad Nazmi Zaidi Moni ${ }^{1}$ and Mohamad Firdaus \\ Basrawi $^{2}$ \\ ${ }^{1}$ Department of Mechanical Engineering, Universiti Teknologi PETRONAS, 32610 Tronoh, Perak. \\ ${ }^{2}$ Faculty of Mechanical Engineering, Universiti Malaysia Pahang, 26600 Pekan, Pahang
}

\begin{abstract}
Oil palm frond has been utilized as a solid biomass fuel for gasification to produce synthesis gas or syngas to be used for heat and power generation. A fuel pre-treatment method by means of extensively-drying OPF blocks at $150^{\circ} \mathrm{C}$ and $200^{\circ} \mathrm{C}$ for 4 hours was implemented to investigate the effects of the fuel in terms of drying efficiency and gasification performances. Tar, pyrolysis oil and condensates were found to be squeezed out by heat during drying, signifying volatilization of fuel at temperatures between water boiling point at $100^{\circ} \mathrm{C}$ and fuel pyrolysis point at $280^{\circ} \mathrm{C}$. Syngas produced from the updraft gasification of extensively-dried OPF blocks was analyzed and tested for sustainable gas flares. The syngas was found to be composed of $16.5 \% \mathrm{CO}$, $10 \% \mathrm{CO}_{2}, 4 \% \mathrm{H}_{2}$ and $0.9 \% \mathrm{CH}_{4}$ and was produced at gasification temperatures lower than that exhibited by normal OPF blocks.
\end{abstract}

\section{Introduction}

Oil palm frond (OPF) is one of the highly-produced biomass in a typical oil palm plantation. Classified as a woody biomass, OPF has an average calorific value of $17.9 \mathrm{MJ} / \mathrm{kg}$, which is fairly attractive as a source for solid biomass fuel1. Recent pattern in OPF fuel research showed that OPF has been utilized as a solid fuel for gasification to produce synthesis gas or syngas and has borne successful results1-9. To become a solid fuel, raw OPF has to undergo a series of processing stages including sizing, sieving, drying and storing. Drying is the most important criteria in solid biomass fuel processing. Normally, any biomass that is subjected for solid fuel production undergoes a drying process to remove excess moisture as a pre-treatment and preservation method to preserve its quality and ensure a longer storage life. For a small batch of feedstock, a drying temperature of $105^{\circ} \mathrm{C}$ for a period of 24 hours is used merely due to the purpose of removing only excess water by exposing the biomass to a temperature just slightly higher than that of boiling water1-9. If the drying temperature is set any higher, the biomass may undergo pre-pyrolysis state where its volatile matters will be released, thus slowly roasting the biomass in the heat, replicating the practice of charcoal-making (slow carbonization) although at a much lower temperature. By average, most plant materials volatilized at around $280^{\circ} \mathrm{C} 11$, whereby pre-pyrolysis state begins at slightly lower temperature, sometimes as low as $200^{\circ} \mathrm{C}$ in the case of wood 12 . With most of the volatile matters removed, the fixed carbon amount in the biomass will relatively be higher than that before extensive drying, hence the term carbonization to describe the process. The objectives of this study were to inspect the changes that occur to OPF blocks when undergoing an extensive drying process at elevated temperatures of $150^{\circ} \mathrm{C}$ and $200^{\circ} \mathrm{C}$ for 4 hours. The gasification of the blocks followed where the effects of using extensively-dried OPF blocks as gasifier fuel to syngas composition and overall quality were studied.

\section{Materials and Methods}

\subsection{Raw material processing}

Fresh OPF of less than two weeks old after pruned were collected from a nearby oil palm plantation. OPF were quickly processed to avoid decomposition due to prolonged storage as suggested by Moni and Sulaiman ${ }^{1}$. Each OPF was cut perpendicularly from its growing axis into $2.5 \mathrm{~cm}$-thick sections using a power circular saw.

Corresponding author: shaharin@utp.edu.my 
The sections were then further reduced into blocks of $2.5 \pm 0.5 \mathrm{~cm}$ in length using a machete, producing small blocks as shown in Fig. 1. The blocks were sun-dried at ambient conditions for 7 days to slowly and naturally remove the excess moisture content trapped within. The blocks were then artificially dried at $105 \pm 0.5^{\circ} \mathrm{C}$ in a convection oven for 24 hours to further remove all remaining moisture and to obtain the equilibrium moisture content value for OPF blocks by weight difference.

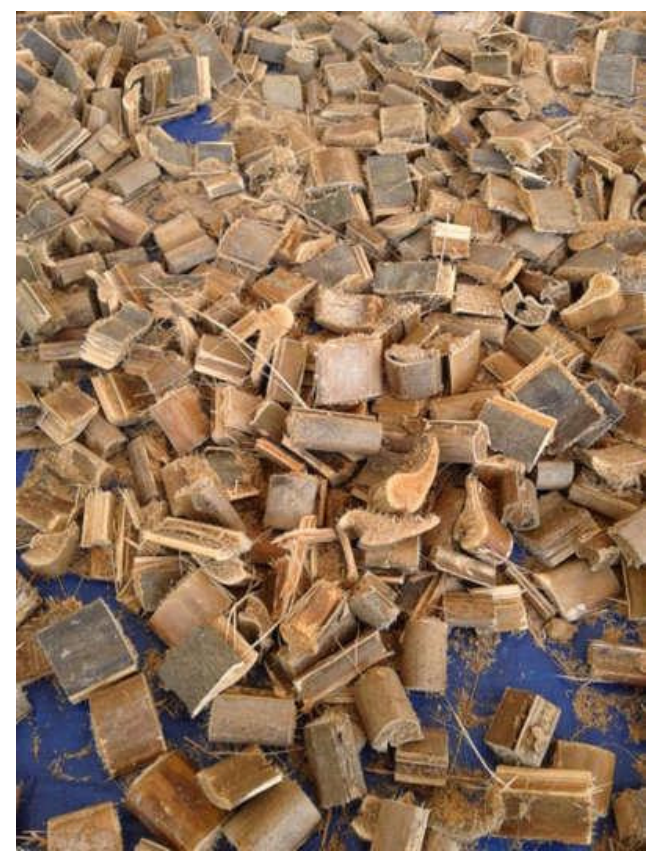

Fig 1. OPF blocks

\subsection{Extensive drying}

Oven-dried OPF blocks were directly heated to $150^{\circ} \mathrm{C}$ and $200^{\circ} \mathrm{C}$ in two separate tests in a convection oven after 24-hour drying at $105 \pm 2^{\circ} \mathrm{C}$. Around $1 \mathrm{~kg}$ of OPF blocks was used for each test, with three repetitions for consistency. Both extensive drying sessions were conducted for 4 hours to inspect the changes during the extensive drying process. Continuous observations were made and recorded throughout the drying period.

\subsection{Gasification}

Extensively-dried OPF blocks were used as a solid fuel for gasification in an updraft gasifier. The arrangement of the updraft gasifier and its downstream equipment is shown in Fig. 2. Around $6 \mathrm{~kg}$ of OPF blocks were required for each gasifier operation. Ambient air was continuously supplied into the gasifier at a rate of 180-220 LPM using a centrifugal blower. Temperature profiles of the gasifier during gasification were taken and recorded using Type$\mathrm{N}$ thermocouples and an 8-port thermocouple reader connected to a desktop computer. Syngas compositions were taken at 1-minute interval along the 60-minute gasifier operation using EMERSON X-STREAM gas analyser and syngas ignitability was constantly tested using a miniature jet burner.

\section{Results and Discussions}

\subsection{Moisture content}

Significant reduction in weight was observed in OPF samples after 7 days of sun-drying at ambient conditions. Averagely, each block lost around 50-60\% of original moisture content. Artificial drying of OPF blocks in a convection oven at $105 \pm 2{ }^{\circ} \mathrm{C}$ for 24 hours revealed that an average of $13 \pm 1 \%$ remaining moisture content was further removed, and this figure was taken as the equilibrium moisture content for OPF blocks when stored at ambient conditions.

After extensive drying, it was assumed that all remaining moisture in OPF blocks had been fully removed with 


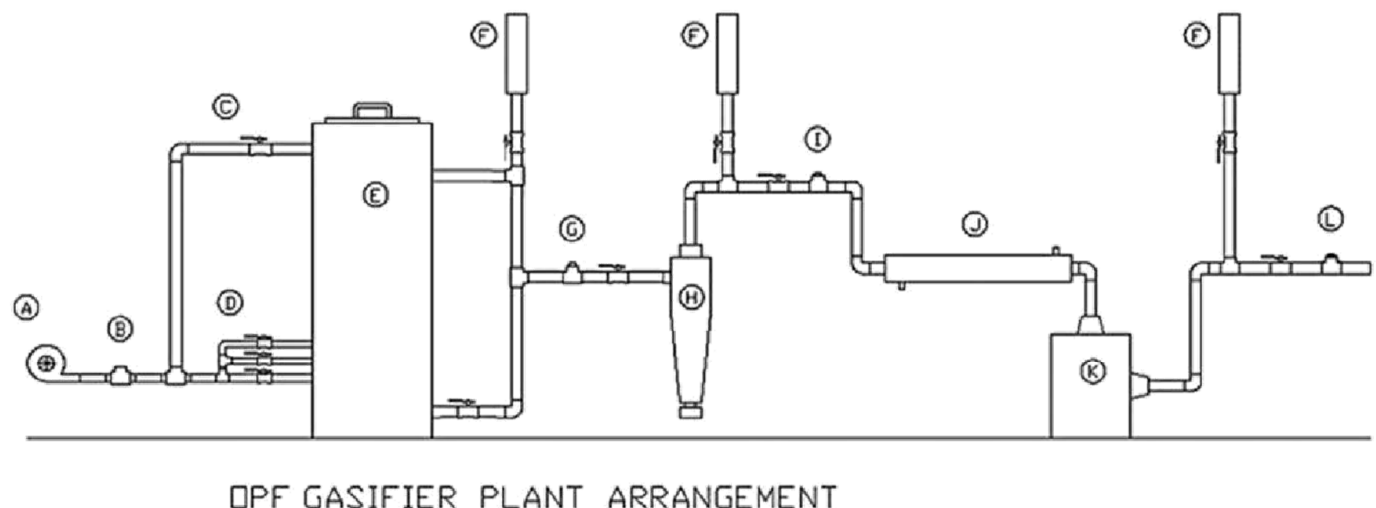

\section{LEGEND}

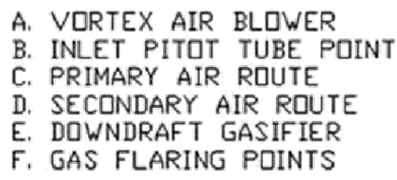

A. VORTEX AIR BLDWER

C. PRIMARY AIR RDUTE

D. SECONDARY AIR ROUTE

F. GAS FLARING POINTS

Fig. 2. OPF gasifier plant arrangement

averagely $4 \%$ more reduction in weight was measured, assumed to be due to removed moisture and the release of light volatiles as a result of the exposure to the elevated drying temperature.

\subsection{Extensive drying}

Oven-dried OPF blocks were subjected to an extended and extensive drying at $150^{\circ} \mathrm{C}$ and $200^{\circ} \mathrm{C}$ in two separate tests for 4 hours. Visual observations made suggested that the blocks underwent pre-pyrolysis process where traces of tarry condensate were detected to form on the internal wall and door surfaces of the convection oven during extensive drying process. Smoky and strong scent of tar was also noticed. The observation was consistent with the behaviour of biomass undergoing pyrolysis where its volatile matters and water contents are 'squeezed out' with applied heat above water boiling point temperature ${ }^{1}$. Some changes on the surface of OPF skin and flesh were observed where their colours changed from bright brown to dark brown darted with black spots indicating the formation of tar and condensates. Small traces of black, sticky substances composed of dehydrated tar and pyrolysis oil were found to form on OPF block surfaces and weakly tie contact surfaces of OPF blocks together. The traces of tar, pyrolysis oil and condensates produced from OPF blocks at $200^{\circ} \mathrm{C}$ drying temperature were observed to be higher than that at $150^{\circ} \mathrm{C}$ due to increased thermochemical activities at higher temperatures close to pyrolysis temperature.

\subsection{Gasification of OPF Blocks}

\subsubsection{Gasification method}

OPF blocks that have undergone the 4-hour extensive drying were fed into the updraft gasifier for gasification. Around $6 \mathrm{~kg}$ of OPF blocks were used in each gasifier operation that lasted for around 60 minutes. Hot gases from the gasifier were directed to a flare point via an exhaust pipeline for ignition tests and sampling.

\subsubsection{Temperature profile}

The hearth temperature during the updraft gasification of OPF blocks was found to be in the range of 400 $650^{\circ} \mathrm{C}$. The temperature range was relatively low when compared to the typical hearth temperature range during the gasification of $\mathrm{OPF}$ fuel that did not undergo any extensive drying process at $750-900^{\circ} \mathrm{C}$ and sometimes up to $1200^{\circ} \mathrm{C}^{1,7}$. The temperatures at drying and pyrolysis zones were found to be between $250-350^{\circ} \mathrm{C}$ respectively, which were also very low compared to typical OPF drying and pyrolysis zone temperatures of around $350-600^{\circ} \mathrm{C}$. 
The low temperature ranges at the given zones were suspected due to suffocation in which the supplied air was at an insufficient rate to keep a healthy combustion.

\subsubsection{Gas ignition}

Sustainable gas flares were obtained during gasification and lasted for a few minute before re-ignition was required. Syngas flares were observed to exhibit faint yellow and orangey flame colour, indicating low amount of unbroken hydrocarbon rings in the syngas stream. Traces of bluish flame that indicated the presence of $\mathrm{H}_{2}$ was not observed. The length of the flare was estimated to reach around $1 \mathrm{~m}$ high from the flare tip and its temperature was measured to be between $400-500^{\circ} \mathrm{C}$ using a handheld thermocouple reader. The gas flare was able to sustain itself without the need for constant re-ignition, indicating the high concentration of flammable gases in the syngas.

\subsubsection{Syngas composition}

The syngas composition analysis showed that by average the syngas produced from extensively-dried OPF blocks contained $16.5 \% \mathrm{CO}, 11.2 \% \mathrm{CO}_{2}, 4 \% \mathrm{H}_{2}$ and $0.9 \% \mathrm{CH}_{4}$. The comparison of the syngas components with typical OPF syngas values is shown in Table 1 while the syngas components production trends are shown in Fig.3.

Table 1. Comparison of syngas components

\begin{tabular}{|l|c|c|c|c|}
\hline \multirow{2}{*}{ OPF Fuel Type } & \multicolumn{4}{|c|}{ Syngas composition (vo. \%) } \\
\cline { 2 - 5 } & $\mathrm{CO}$ & $\mathrm{CO}_{2}$ & $\mathrm{H}_{2}$ & $\mathrm{CH}_{4}$ \\
\hline Extensively-dried & 16.5 & 10 & 4 & 0.9 \\
\hline Normally-dried & 18.0 & 10 & 10 & 1.4 \\
\hline \% difference & 8.3 & 0 & 60 & 36 \\
\hline
\end{tabular}

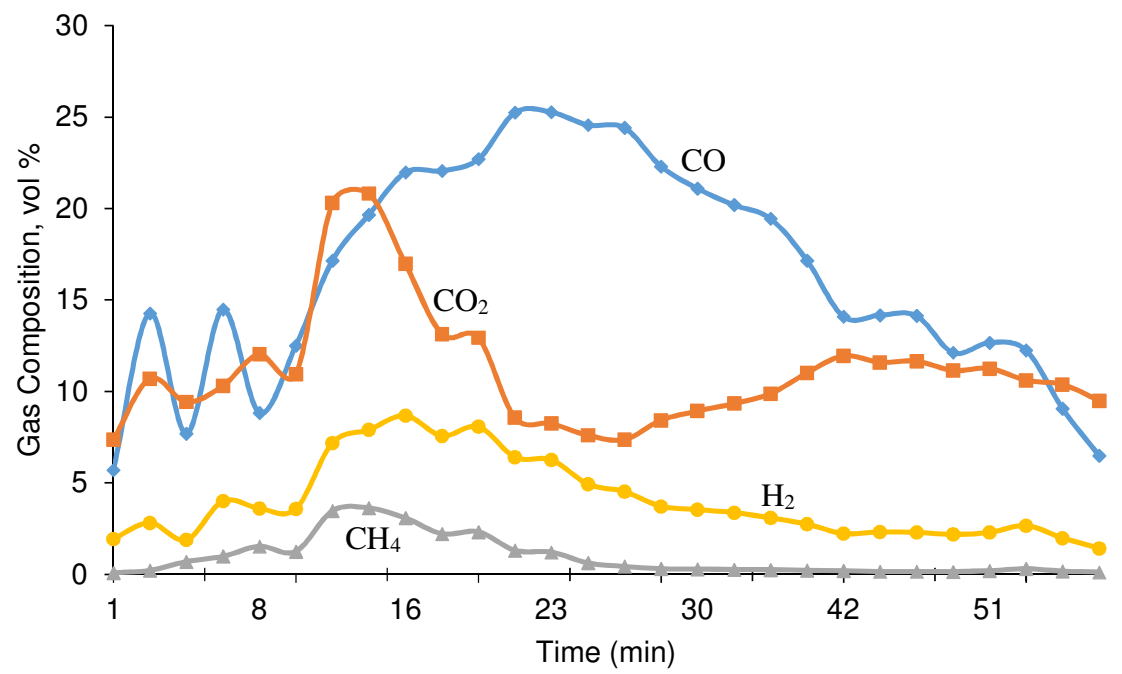

Fig. 3. Syngas composition as a function of gasifier operating time

The volume $\%$ of $\mathrm{CO}, \mathrm{H}_{2}$ and $\mathrm{CH}_{4}$ were found to be lower than the typical values while the volume $\%$ of $\mathrm{CO}_{2}$ was found to be equivalent. In Fig. 2, it can be observed that all syngas components experienced drops in production after reaching their peaks after around 15-20 minutes of gasifier operation. The slightly increasing amount of $\mathrm{CO}_{2}$ after 30 minutes of operation showed that complete combustion was occurring, causing other syngas components to experience drops in concentrations. This may due to the decreasing amount of fuel after being consumed in combustion while the supplied air was maintained at the same flow rate, causing the air-fuel equivalence ratio to increase nearing to 1.0 where substoichiometric combustion ceased and stoichiometric combustion took place. The low productions of $\mathrm{CO}, \mathrm{H}_{2}$ and $\mathrm{CH}_{4}$ can be explained by examining the thermochemical reactions that were responsible for their formations:

$$
\mathrm{C}+\mathrm{O}_{2} \rightarrow \mathrm{CO}_{2}
$$




$$
\begin{gathered}
\mathrm{C}+\mathrm{H}_{2} \mathrm{O} \rightarrow \mathrm{CO}+\mathrm{H}_{2} \\
\mathrm{C}+2 \mathrm{H}_{2} \mathrm{O} \rightarrow \mathrm{CO}_{2}+2 \mathrm{H}_{2} \\
\mathrm{CO}+\mathrm{H}_{2} \mathrm{O} \rightarrow \mathrm{H}_{2}+\mathrm{CO}_{2} \\
\mathrm{C}+\mathrm{H}_{2} \mathrm{O} \rightarrow \frac{1}{2} \mathrm{CH}_{4}+\frac{1}{2} \mathrm{CO}_{2}
\end{gathered}
$$

Reactions (3.1) takes place at the oxidation stage where $\mathrm{O}_{2}$ is consumed combustion to provide heat for fuel drying, to break up weak chemical bonds in pyrolysis stage and raise the overall reactor temperature for reactions (3.2) to (3.4) to occur. Reactions (3.2) and (3.3) are water-gas shift reactions, the principal gasification reactions, favouring high temperature and low pressure to occur. Reaction (3.4) is a part of water-gas shift and occurs at low temperature for $\mathrm{H}_{2}$ production. Reaction (3.5) is methanation reaction where $\mathrm{CH}_{4}$ is produced ${ }^{1}$. Almost all of the reactions require $\mathrm{H}_{2} \mathrm{O}$ to occur - a condition that was scarcely achieved during the gasification of extensivelydried OPF blocks due to the removal of most moisture content from the OPF blocks during extensive drying. As a result, most of the reactions occur slowly depending to the available moisture content in the supplied ambient air into the gasifier, thus reducing the concentration of syngas components. In the case of $\mathrm{CO}_{2}$, since air and hot char were available in high amount, the production of $\mathrm{CO}_{2}$ was not affected. These observations suggested the important role of water in gasification especially for the production of $\mathrm{H}_{2}$ from water-gas shift reaction, indicating that gasification feedstock that is too dry may not be beneficial for optimum syngas production. Therefore, feedstock with moisture content of less than $20 \%$ is recommended for quality syngas production, where the retained moisture content is low enough to maintain gasification temperature and to prevent condensates formation but high enough to initiate water-gas shift reactions from the exposure to hot char at the gasifier hearth to produce $\mathrm{H}_{2}$ and $\mathrm{CH}_{4}$.

\section{Conclusions}

Although pre-treating OPF blocks by extensive drying at high temperatures has reduced the volatile counts and increased the amount of carbon in fuel, the complete removal of water was found to cause gasification efficiency to drop and therefore affect the quality of syngas in terms of $\mathrm{CO}$ and $\mathrm{H}_{2}$ fractions and gas ignitability. Furthermore, extensive drying of OPF blocks showed that tar, pyrolysis oil and condensates were 'squeezed' out by heat in gaseous form before reforming as liquid within the oven. This may contaminate the oven with hard stains and may affect the overall oven efficiency due to possible tar accumulation along the oven's ventilation points. In terms of gasification efficiency, mixing the extensively-dried OPF blocks with normally-dried OPF blocks may improve the overall fixed carbon amount to increase $\mathrm{CO}$ production while with adequate $\mathrm{H}_{2} \mathrm{O}$ content in OPF block, the production of $\mathrm{H}_{2}$ may also increase.

\section{References}

1. M.N.Z. Moni, S.A. Sulaiman, Downdraft Gasification of Oil Palm Frond (Lambert Academic Publishing, Germany, 2012)

2. S.A. Sulaiman, S. Balamohan, M.N.Z. Moni, S.M. Atnaw, A.O. Mohamed "Study on the Feasibility of Oil Palm-Fronds for Biomass Gasification" (5 $5^{\text {th }}$ IESE, Turkey 2010)

3. S.A. Sulaiman, M. Karim, M.N.Z. Moni, S.M. Atnaw, "Gasification Study on Different Plant-Based Biomass Materials" ( $3^{\text {rd }}$ ICPER, Kuala Lumpur, 2012).

4. Atnaw S M, S.A. Sulaiman, S. Yusup, Jour. App. Sci. 11, pp. 1913-1920 (2011)

5. S.M. Atnaw, S.A. Sulaiman, M.N.Z. Moni, "Experimental Study on Temperature Profile of Fixed - Bed Gasification of Oil- Palm Fronds" (4 ${ }^{\text {th }}$ IMAT, Melaka, 2011)

6. F.M. Guangul, S.A. Sulaiman, A. Ramli, Bioresour. Technol. 126, pp 224-232 (2011)

7. M.N.Z. Moni, S.A. Sulaiman, "Downdraft Gasification of Oil Palm Frond: Effects of Temperature, Operation Time" ( $3{ }^{\text {rd }}$ ICPER, Kuala Lumpur, 2011)

8. F.M. Guangul, S.A. Sulaiman, M.N.Z. Moni, S.M. Atnaw, R.E. Konda, "Investigation of the Hygroscopic Property of Oil Palm Fronds for Gasification Process", ( ${ }^{\text {rd }}$ ICPER, Kuala Lumpur, 2011)

9. M.N.Z. Moni, S.A. Sulaiman "Method of Processing Oil Palm Frond into Biomass Fuel for Downdraft Gasification," (3 ${ }^{\text {rd }}$ ICPER, Kuala Lumpur, 2011)

10. A.B. Nasrin, A.N. Ma, Y.M. Choo, S. Mohamad, M.H. Rohaya, A. Azali, Z. Zainal, American Jour. App. Sci. 5 (3) pp. 179-183 (2011)

11. Y. Shinogi, Y. Kanri, Bioresour. Technol. 90 pp. 241-247 (2003)

12. H. Pakdel, C. Roy, Energy \& Fuels 5, pp. 427-436, (1991) 